\title{
Study on Mechanical, Thermal and Electrical Characterizations of Nano-SiC/Epoxy Composites
}

\author{
By Tianle ZHOU, ${ }^{1,2, *}$ Xin $W A N G,{ }^{1}$ Mingyuan $G U^{3}$ and Dangsheng $X I O N G^{2}$
}

This report covers the results of a study on evaluating the effect of nano-SiC particles on mechanical, thermal and electrical properties of epoxy by lap shear, TGA, DSC and electrical tests. Epoxy composites filled with micro-SiC particles were also studied for comparison. The mechanisms of performance improvement were discussed in detail. The results showed that with identical loading, silane treated nano-SiC filled nanocomposites have the best properties. The volume resistivity decrease, dielectric constant $\varepsilon$ increase and loss tangent $\tan (\delta)$ increase by addition of silane treated nano-SiC particles are smaller than those by the other fillers. Silane treatment of nanoparticles improves each performance, including increases shear strength, thermal stability, volume resistivity and decreases $\varepsilon$ and $(\delta)$. The addition of nano-SiC particles remarkably improves shear strength, $\varepsilon$ and $\tan (\delta)$, while slightly enhances thermal stability of epoxy. 8 vol. \% silane treated nano-SiC/epoxy composite has the highest shear strength $10.6 \mathrm{MPa}$ with the maximum enhancement, $80 \%$, over the neat resin. It also has good temperature independence of dielectric properties and enough volume resistivity, which meet the demand of some microelectronics materials.

KEY WORDS: SiC/Epoxy Composites / Nanocomposites / Mechanical Properties / Thermal Properties / Dielectric Properties /

Using inorganic nanofillers to produce high performance nanocomposites is attaining increasing interest. An interface interaction zone of $1 \mathrm{~nm}$ thick represents roughly 0.3 vol. $\%$ of microcomposites, whereas it can reach $30 \mathrm{vol} \%$ of nanocomposites. $^{1}$ The contribution of interaction zone provides diverse possibilities of performance tailoring and is able to influence the performance to a much greater extent under rather low nanofiller loading. Studies have shown that the performance of polymeric materials can be improved by adding a small amount $(<5 \mathrm{wt} \%)$ of inorganic nanofillers without compromising weight or processability of the composites. ${ }^{2-8}$ The challenges are to obtain remarkable improvements in the interfacial bonding between polymer matrix and nanofillers. Stronger interfacial bonding will impart better properties.

$\mathrm{SiC}$ is a large band gap semiconductor $(>2 \mathrm{eV})$ with good mechanical properties, high thermal stability (melting point $\left.\sim 2800^{\circ} \mathrm{C}\right)$, high thermal conductivity $(\sim 390 \mathrm{~W} / \mathrm{mK})$, and high electric break down field $\left(\sim 4 \times 10^{8} \mathrm{~V} / \mathrm{m}\right)$. Such properties make $\mathrm{SiC}$ an attractive candidate for high temperature and high power applications in electronic industry. ${ }^{9}$ Epoxy resins also exhibit versatile applications in electrical and electronic industries, e.g., encapsulant of electrical circuits and electronic devices. Some studies involving the effect of nano-SiC particles on tensile response (stiffness and strength), ${ }^{4}$ friction and wear, ${ }^{5}$ curing process and curing kinetics ${ }^{10}$ of epoxies have been conducted. Recently, developments in semiconductor and electronic packages require electrically insulating materials possessing high strength, good thermal stability, and low dielectric constant. An earlier study, ${ }^{6}$ preparing three samples containing $0.5,1$, and $1.5 \%$ of nano-SiC particles by weight of
SC-15 epoxy resin, indicated that $1 \%$ loading yields the maximum improvement in thermal stability and flexural response (stiffness and strength). But hardly any published detailed papers are available to date on the thermal stability of nano-SiC/epoxy composites with high filler content, as well as lap shear strength and electrical properties. Therefore, the aim of this paper was to evaluate the effect of nano-SiC particles on lap shear strength and electrical properties of the epoxy, and study the thermal stability of epoxy composites with high nanoSiC loading (e.g., $20 \mathrm{wt} \%, 20 \%$ by weight of composite). For comparison, epoxy composites filled with micro-SiC particles were also studied.

Adding nanoparticles is not bound to bring about positive effect. To give full play of nanoparticles, in this study, nano$\mathrm{SiC}$ particles were pretreated with amino silane coupling agent, as it would increase hydrophobic characteristic of the nanoparticles and its amino groups would take part in the curing reaction of epoxy, besides breaking apart the nanoparticle agglomerates. Thus strong filler/matrix interfacial chemical bonding would be established, which might improve overall performance of the nanocomposites. Therefore, in this paper, another purpose is to evaluate the effect of silane treatment on the performance of nanocomposites.

\section{EXPERIMENTAL}

\section{Materials \\ Epoxy resin used in this work was a nominally difunctional epoxy resin, Epon 828, supplied by Shanghai Resin Co. Epon 828 is, basically, Diglycidyl ether of bisphenol-A glycidol}

\footnotetext{
${ }^{1}$ Key Laboratory for Soft Chemistry \& Functional Materials of Ministry Education, Nanjing University of Science \& Technology, Nanjing 210094, China ${ }^{2}$ Department of Materials Science \& Engineering, Nanjing University of Science \& Technology, Nanjing 210094, China

${ }^{3}$ State key laboratory of MMCs, Shanghai Jiao Tong University, Shanghai 200240, China

*To whom correspondence should be addressed (Tel: +86-025-84313421, Fax: +86-025-84313421, E-mail: ztltianle999@ hotmail.com).
} 
ether epoxy resin (DGEBA) with epoxy value of $0.48-0.52$ $\mathrm{mol} / 100 \mathrm{~g}$ and density of $1.11 \mathrm{~g} / \mathrm{cm}^{3}$. Curing agent utilized was 2-ethyl-4-methylimidazole (EMI-2,4) supplied by Beijing Chemical Reagent Co. The DGEBA/EMI-2,4 ratio employed was 100:4. $\beta$-SiC particles with average particle size of $50 \mathrm{~nm}$ and $0.75 \mu \mathrm{m}$ were obtained from Karl Co. Before stored in desiccators, particles were dried at $383 \mathrm{k}$ for $24 \mathrm{~h}$ in vacuum to eliminate the agglomeration caused by hygroscopic absorption, as well as removing planar water, which would hinder the interaction between coupling agent and particles. Micrographs of the SiC particles can be seen in our previous work. ${ }^{11}$ The nano-SiC and micro-SiC particles are approximately spherical and irregular polyhedral in shape, respectively. SiC particles without silane treatment are seriously and unevenly agglomerated. Amino silane coupling agent, $\gamma$-aminopropyl-triethoxysilane (A1100, boiling point $\sim 217^{\circ} \mathrm{C}$ ), was obtained from Shanghai Chemical Reagent Co. Aluminum (Al), sodium hydroxide, and deionized water, all of laboratory grade, were obtained from indigenous sources. Other agents utilized were analytically pure grade and were supplied by Beijing Chemical Reagent Co.

\section{Surface Modification of SiC Particles}

Surface treatment of SiC particles using A1100 involved (i) making a silane-absolute ethanol solution at a selected concentration, and the amounts of silane coupling agent used were $10 \%$ by weight of the nano-SiC particles and $3 \%$ by weight of the micro-SiC particles, (ii) adding $\mathrm{SiC}$ particles to the solution and stirring with a magnetic stirrer at $333 \mathrm{k}$ for $30 \mathrm{~min}$, in addition, dispersing the solution added with nanoparticles by sonication for $1 \mathrm{~h}$ since nanoparticles are known to agglomerate easily, (iv) rinsing with absolute ethanol by filtration, and (iv) drying at $383 \mathrm{k}$ for $1 \mathrm{~h}$ in vacuum. Then the silane treated particles were stored in desiccators.

\section{Preparation of $\mathrm{SiC} /$ Epoxy Composites}

The SiC/epoxy composites were prepared by solution blending and casting method, which involved (i) stirring DGEBA-absolute ethanol solution at $353 \mathrm{k}$ with magnetic stirrer for $20 \mathrm{~min}$, (ii) adding appropriate amount of surface treated or untreated $\mathrm{SiC}$ particles to the solution and continuing stir for $30 \mathrm{~min}$, in addition, sonicating the solution added with nanoparticles for $1 \mathrm{~h}$ to ensure good homogeneity, (iv) cooling to $333 \mathrm{k}$, (iv) adding EMI-2,4, which is $4 \%$ by weight of DGEBA, to the mixture and continuing stir for $10 \mathrm{~min}$, (v) casting the mixture in mould, (vi) repeatedly degassing the mixture in vacuum drying oven at $333 \mathrm{k}$ until no air bubble appears on the surface of the mixture, (vii) curing the mixture at $338 \mathrm{k}$ for $1 \mathrm{~h}, 393 \mathrm{k}$ for $1.5 \mathrm{~h}$, and $433 \mathrm{k}$ for $1.5 \mathrm{~h}$, and the curing time for nanocomposites should be prolonged moderately since nano-SiC particles would delay the cure reaction as reported in our previous work, ${ }^{10}$ and (viii) cooling to room temperature, then demoulding.

Micrograph of fracture surface, prepared from epoxy composites with 14 vol. \% silane treated nano-SiC particles, is shown in Figure 1. Silane treated nano-SiC particles are seen

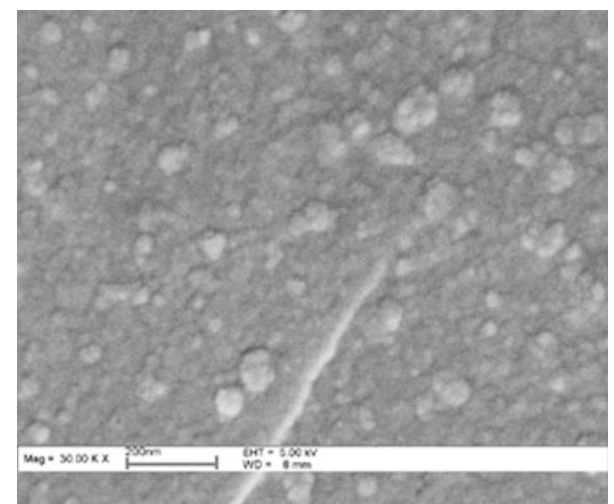

Figure 1. FE-SEM micrograph of fracture surface of epoxy composite containing $14 \mathrm{vol}$. \% silane treated nano-SiC particles.

to be separated and uniformly embedded in the matrix. No obvious naked particles and inorganic clusters presents, indicating good interfacial adhesion between the particles and polymer matrix after silane pretreatment.

\section{Preparation of Lap Shear Joints}

Aluminum (Al, $1.6 \mathrm{~mm}$ thick) substrates were degreased with acetone, followed by a hot water rinse. Then after a sodium hydroxide deoxidization and a sodium hydroxide anodizaion both followed by a cold water rinse, the substrates were dried with hot air.

In this study, aluminum to aluminum (Al-Al) adhesive joints were prepared. Specimens from each category (net, and various filler contents) were coated onto two thoroughly cleaned Al substrates $(100.6 \mathrm{~mm} \times 25.4 \mathrm{~mm} \times 1.6 \mathrm{~mm})$ with a bar coater at a coat weight of $20 \mathrm{~g} / \mathrm{m}^{2}$. The coated samples were dried in an oven for $3 \mathrm{~min}$ at $80^{\circ} \mathrm{C}$ and then joined together with a lap area of $25.4 \times 12.7 \mathrm{~mm}^{2}$ and were pressed by a $2 \mathrm{~kg}$ roller passing over thrice. The sandwiched samples were exposed to a cure cycle following aforesaid curing rule and then cooled to room temperature.

\section{Characterization}

Shear strength of the lap joints were determined using a Zwick T1-Fr020TN.A50 UTM machine as per ASTM D1002 test method. Five specimens from each category (net, and various filler contents) were tested and the average was reported. The tests were performed at a separation rate of $1.27 \mathrm{~mm} / \mathrm{min}$. Lap shear strength was recorded as the peak stress at specimen failure and calculated as:

$$
\begin{aligned}
& \text { Lap shear strength }(\mathrm{kPa}) \\
& \quad=\text { Shear force }(\mathrm{kN}) / \text { Bonded area }\left(\mathrm{m}^{2}\right)
\end{aligned}
$$

Shear fracture morphological studies were carried out also using FE-SEM (LEO1550). The fracture surfaces were coated with a thin gold layer before FE-SEM.

Thermal degradation of the pure system and SiC/epoxy composites were characterized by TGA (Perkin-Elmer Co., TGA-7 system) at a scan rate of $10 \mathrm{~K} / \mathrm{min}$ to $1023 \mathrm{~K}$ in $\mathrm{N}_{2}$ atmosphere. 
Glass transition Temperature $\left(T_{\mathrm{g}}\right)$ of the pure system and $\mathrm{SiC} /$ epoxy composites were determined by conventional DSC (Perkin-Elmer Co., DSC-7 system). A sample of approximately $10 \mathrm{mg}$ was weighed accurately into an aluminum DSC sample pan and then covered with an aluminum lid. The entire operation was carried out in a dry chamber under a nitrogen flow rate of $10 \mathrm{~mL} / \mathrm{min}$. The DSC was calibrated with high purity indium and $\alpha-\mathrm{Al}_{2} \mathrm{O}_{3}$ was used as reference material. Exotherm baseline was corrected via data on empty aluminum pan. Dynamic DSC measurements were performed at a heating rate of $20 \mathrm{~K} / \mathrm{min}$ over a temperature range of 303 to $623 \mathrm{~K}$. The reaction was considered to be complete when the curve leveled off to a baseline. The cured sample was left in the DSC cell and cooled to room temperature, and then it was scanned at $20 \mathrm{~K} /$ min again to determine the $T_{\mathrm{g}}$ of the reacted product. The inflection point of the heat flow step of the second diagram was defined as DSC $T_{\mathrm{g}}$.

Capacitance and loss tangent $\tan (\delta)$ of the pure system and $\mathrm{SiC} /$ epoxy composites were measured using HP4284A multifrequency LCR meter. The measurements were performed at $1 \mathrm{MHz}$. Dimension of the specimens used is about $35 \mathrm{~mm} \times$ $35 \mathrm{~mm}$ with a thickness varying from 1 to $2 \mathrm{~mm}$. Electrical conductivity adhesive (epoxy filled with silver flakes) tapes were used as end electrodes. A set of five specimens was tested for each material. Dielectric constant $\varepsilon$ of the material is given by the following equation,

$$
\varepsilon=\frac{c}{(A / d) \varepsilon_{0}}
$$

Where $c$ is the capacitance of the specimen, $A$ is the area of contact electrode to the specimen, $d$ is the thickness of the specimen, and $\varepsilon_{0}$ is the vacuum dielectric constant, $\varepsilon_{0}=$ $8.84 \times 10^{-12} \mathrm{C}^{2} /\left(\mathrm{N} \cdot \mathrm{m}^{2}\right)$.

Volume resistance of the pure system and $\mathrm{SiC} /$ epoxy composites were measured at room temperature using HP4329A impedance measuring meter.

\section{RESULTS AND DISCUSSION}

\section{Lap Shear Strength}

Lap shear test results for Al-Al joints, as shown in Figure 2, were used to evaluate the shear strength of the composites. These systems all failed within the composites. The lap shear strength of composites is found to initially increase with the increasing loading level of $\mathrm{SiC}$ particles, explained in terms of strengthened cohesive strength and interaction between the substrates and the composite adhesives, reach the maximum, and then continually decrease with the increasing filler content, indicating that over-dose of $\mathrm{SiC}$ particles would do harm to the shear strength of the composites.

It can be seen that silane pretreatment of $\mathrm{SiC}$ particles contributes to significant enhancement in the strength of composites. Such enhancement comes from the fact that silane coupling agent forms a transition layer between resin and fillers, which efficiently transfers stress, timely eliminates the stress concentration, as well as strengthening the cohesive strength.

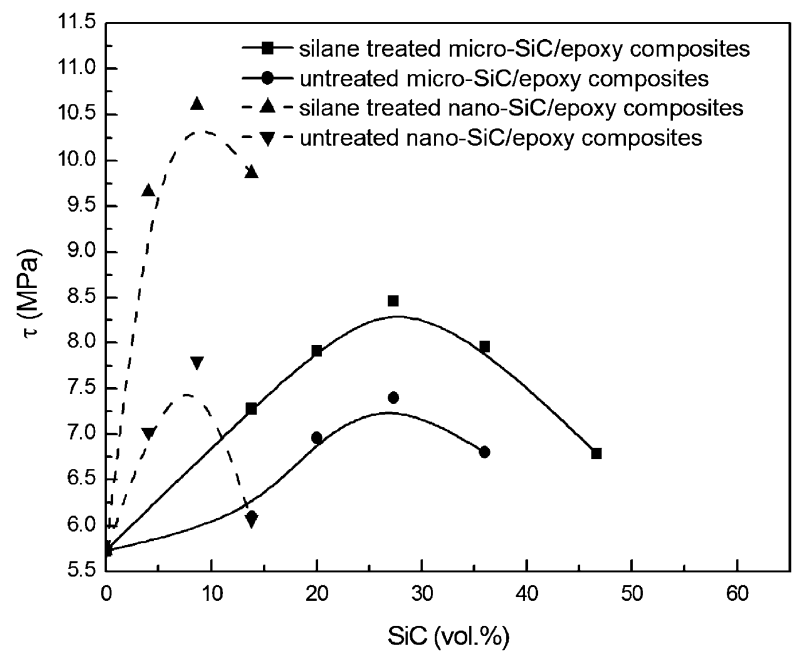

Figure 2. Plot of shear strength of SiC/epoxy composites vs. volume fraction of SiC. Lines are given only for showing the tendency.

It also can be seen that nanocomposites demonstrate a sharp improvement in shear strength over microcomposites. As silane treated nano-SiC content reached 8 vol. \%, the shear strength of nanocomposites increased to $10.6 \mathrm{MPa}$ with the enhancement significantly improved to $80 \%$ over the neat resin, while the shear strength of microcomposites increased to $8.46 \mathrm{MPa}$ with the corresponding enhancement over neat resin is $50 \%$, as the silane treated micro-SiC content reached $27.3 \mathrm{vol} . \%$. This result indicates that nanocomposites have higher strength with lower filler content as compared with microcomposites.

In addition, with identical low loading, nanocomposites perform much better, viz. have higher strength, than microcomposites. Our understanding is that nano-SiC particles having nano-sized dimensions provide relatively more interaction with polymer chains. Furthermore, if dispersed properly, spherical nanoparticles can sit comfortably within the polymer chains and coils which have similar dimensions. If the center of nanoparticles is close to the radius of gyration of the polymer coils, the number of atoms at the surface will increase significantly. This in turn will also enhance the reactivity between particles and polymer. ${ }^{6}$ Therefore, more reactivity will translate into increased changes in polymer properties such as what we have observed herein with our shear test results with spherical nanoparticle infusion.

The shear fracture morphology of epoxy composites are showed in Figure 3. It is noticed that nanocomposites are more of a ductile nature as opposed to a brittle failure in case of microcomposites. The microcomposites fracture in a brittle manner accompanied by debonding inclusions and voids associated with particles breaking off, indicating poor filler/ matrix interaction. Large plate-like areas of material being torn out of the specimen are also displayed in Figure 3a. Evidently, particle debonding and the small size of void formed cause the extensive yielding of the surrounding matrix during loading. ${ }^{12}$ For the nanocomposites, shear failure propagated across Figure $3 b$. Smaller limitation of the plastic deformation on 

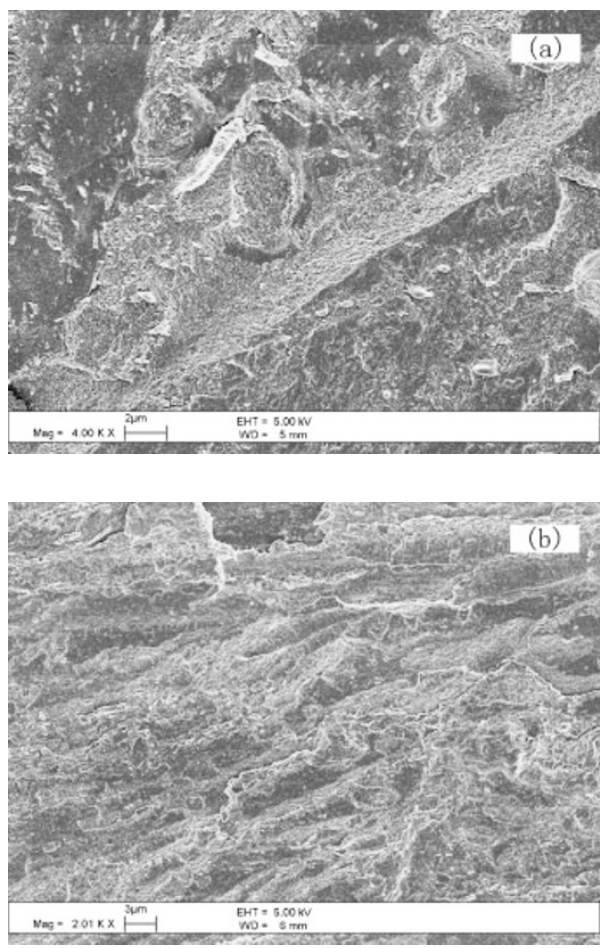

Figure 3. FE-SEM micrographs of shear fracture of epoxy composites containing 8 vol. \% silane treated (a) micro-SiC and (b) nano-SiC particles.

the crack initiation stage and less brittle fracture of the material cause higher shear strength as demonstrated above.

\section{Thermal Stability}

Since 8 vol. \% silane treated nano-SiC/epoxy composite has the maximum shear strength, TGA and DTG curves of SiC/ epoxy composites with $20 \mathrm{wt} \%$ (i.e., $8 \mathrm{vol}$. \%) filler content, as shown in Figure 4, were used to evaluate thermal stability. The curves in Figure 4 are similar, indicating that the content and size of SiC don't affect the degradation pattern of the $\mathrm{SiC} /$ epoxy composites. There is no remarkable weight loss below $200{ }^{\circ} \mathrm{C}$, indicating good moisture resistance of the studied systems.

All the TGA curves have only one step degradation and it is a common practice to consider the peak degradation temperature as the thermal stability for such cases. ${ }^{6}$ In this study, the half-weight-loss temperature $T_{\text {half }}$, and the maximum thermal degradation temperature $T_{\max }$, at which the weight losing rate is the maximum, were summarized in Table I. It is a common practice to consider $T_{\text {half }}$ or $T_{\max }$, the peak of the derivative curve (DTG curve), as an indicator for the beginning of structural decomposition. ${ }^{4,6}$ In addition, the thermal degradation onset temperature $T_{\text {onset }}$, determined from the intersection of the two tangents at the first inflection point, the maximum weight losing rate $R_{\max }$ and the char residual at $750^{\circ} \mathrm{C}$ were also summarized in Table I.

Generally, low molecular weight species are decomposed at low temperature, whilst molecule with high crosslinking density would be decomposed at higher temperature. There-
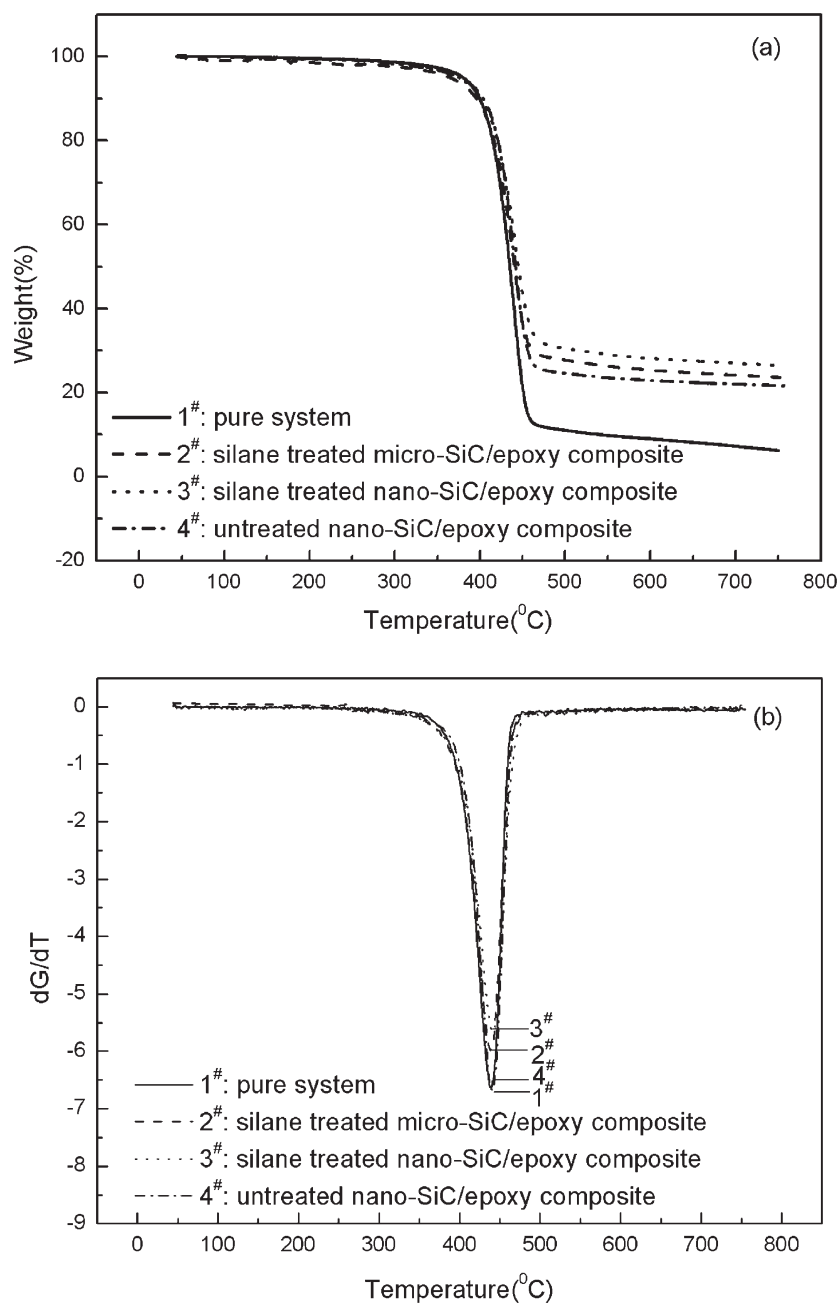

Figure 4. (a) TGA and (b) DTG curves of the pure system and epoxy composites containing $20 \mathrm{wt} \%$ (i.e., 8 vol. \%) SiC particles.

fore, it is reasonable to believe that the evaporation of free A1100 molecules (boiling point $\sim 217^{\circ} \mathrm{C}$ ) leads to the lower $T_{\text {onset }}$ of silane treated nano-SiC/epoxy composites with respect to that of untreated nano-SiC/epoxy composites.

When nano-SiC particles are introduced into system, there would, on the one hand, result in a decrease in thermal stability, which can be due to the weakened van der Waals interaction between polymer chains ${ }^{4}$ and the lowered $T_{\mathrm{g}}$, as shown in Figure 5. There could be three reasons for the lowering effect of nano-SiC particles on $T_{\mathrm{g}} \cdot{ }^{6,13,14}$ First, nano-SiC particles inhibit the cure reaction as reported before, ${ }^{10}$ resulting in a lower crosslinking density in epoxy matrix and, therefore, a lower $T_{\mathrm{g}}$. Usually $T_{\mathrm{g}}$ decreases with decreasing crosslinking density of epoxy because of the decreasing restriction in molecular mobility imposed by crosslinking. This effect can be understood in terms of increasing free volume. ${ }^{6}$ Second, nanoparticles have large surface area. The large particles/resin interface creates extra free volume and, therefore, assists the large-scale segmental motion of polymer, and thereby resulting in a lower $T_{\mathrm{g}}$. Third, the agglomeration of nanoparticles. The difficulty to disperse nanoparticles remarkably increases with 
Table I. Thermal stabilities of the pure system and SiC/epoxy composites with 20 wt \% (i.e., 8 vol. \%) filler content as determined from TGA and DTG curves ( $R_{\max }$ values were evaluated with respect to the total sample mass)

\begin{tabular}{|c|c|c|c|c|c|}
\hline Sample & $\begin{array}{c}T_{\text {onset }} / \\
{ }^{\circ} \mathrm{C}\end{array}$ & $\begin{array}{l}T_{\text {half }} / \\
{ }^{\circ} \mathrm{C}\end{array}$ & $\begin{array}{l}T_{\max } / \\
{ }^{\circ} \mathrm{C}\end{array}$ & $\begin{array}{c}R_{\max } / \\
\%{ }^{\circ} \mathrm{C}^{-1}\end{array}$ & $\begin{array}{c}\text { Char residual at } 750^{\circ} \mathrm{C} / \\
\%\end{array}$ \\
\hline Pure system & 413.9 & 435.2 & 439.0 & 6.73 & 6.21 \\
\hline treated micro-SiC/epoxy composite & 414.1 & 440.8 & 439.0 & 5.98 & 23.66 \\
\hline untreated nano-SiC/epoxy composite & 417.0 & 441.8 & 440.7 & 6.68 & 20.00 \\
\hline treated nano-SiC/epoxy composite & 416.3 & 445.2 & 442.0 & 5.68 & 26.51 \\
\hline
\end{tabular}

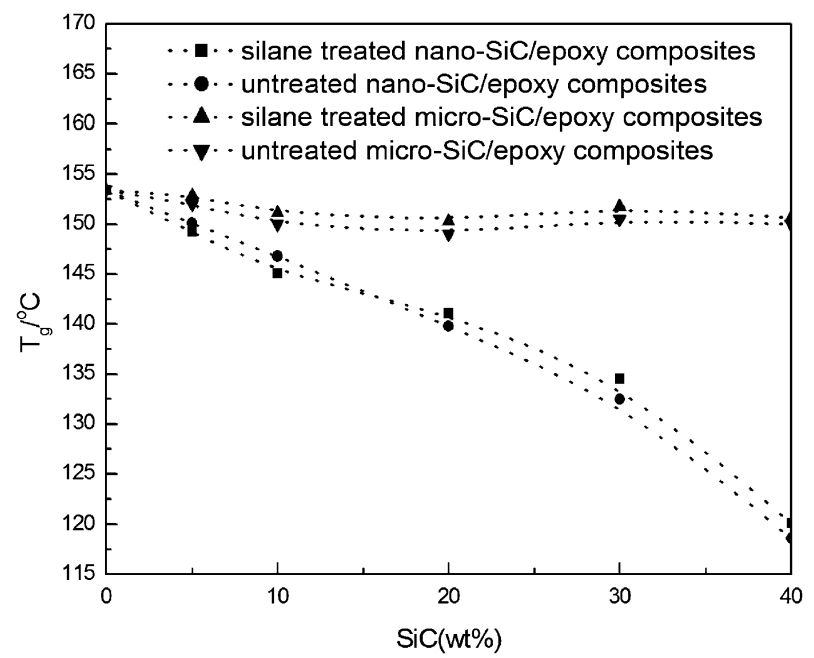

Figure 5. Plot of $T_{\mathrm{g}}$ vs. mass fraction of SiC. Dotted lines are given only for showing the tendency.

increasing loading. Once nanoparticles agglomerate, the interactions are more between particles rather than particle and resin. The agglomerated particles can not impose any restrictions on molecular mobility, and thereby resulting in a lower $T_{\mathrm{g}}$.

Previous studies ${ }^{7,8}$ suggested that high thermal stability of polymers in the presence of fillers is due to the hindered thermal motion of polymer molecular chains. Chemical bonds established between nano-SiC particles and epoxy strengthen the interface interaction, which would restrict the thermal motion of epoxy resin chains, and therefore, on the other hand, the addition of nano-SiC particles can also increase the thermal stability. However, the final result of nano-SiC particles on the thermal stability of nanocomposites arises from antagonistic competition of the two effects.

The overall inference from the small variation of $T_{\text {half }}$ and $T_{\max }$ in Table I was that the addition of SiC particles slightly enhances thermal stability of epoxy, and the improvement effect follows the sequence: treated micro-SiC $<$ untreated nano-SiC $<$ treated nano-SiC. $T_{\text {half }}$ of epoxy with silane treated nano-SiC infusion is increased by $10{ }^{\circ} \mathrm{C}$, the maximum improvement effect, with respect to that of neat epoxy.

As seen in Table I, epoxy with untreated nano-SiC particles degraded with the highest $R_{\max }$, illuminating that silane treatment of nano-SiC particles reduces the rate of degradation and helps to increase thermal stability of the nanocomposites. As reported in our previous work, ${ }^{10}$ amino silane coupling agent lessens the $T_{\mathrm{g}}$ depression at high nano-SiC particle contents ( $>15 \mathrm{wt} \%$ ), as shown in Figure 5, therefore, it is understandable for amino silane coupling agent to lessen the thermal stability depression effect of nano-SiC particles in our present study with $20 \mathrm{wt} \%$ filler content. On the other hand, coupling agent helps in establishing chemical bonds between particles and polymer matrix, thereby contributing to the thermal stability improvement effect. As the result of these two positive effects, silane treatment of nano-SiC particles improves the thermal stability of nanocomposites.

Weaker interface interaction in microcomposites leads to less improvement in thermal stability than that of nanocomposites, meanwhile, the addition of silane treated micro-SiC particles slightly decreases $T_{\mathrm{g}}$ of the composites, as shown in Figure 5, resulting in slight decrease in thermal stability. As the result of antagonistic competition of the two effects, thermal stability follows the sequence: pure system $<$ treated microSiC/epoxy composites.

\section{Electrical Properties}

Small dielectric constant $\varepsilon$ and low loss tangent $\tan (\delta)$ are desirable to increase signal propagation velocity. Figure 6 shows $\varepsilon$ and $\tan (\delta)$ of the pure system and SiC/epoxy composites at room temperature and at $1 \mathrm{MHz}$ frequency.

It is understandable to notice in Figure 6 that $\varepsilon$ and $\tan (\delta)$ increase with increasing $\mathrm{SiC}$ particles content, since $\varepsilon$ and $\tan (\delta)$ of $\mathrm{SiC}$ (42 and 0.05 , as measured at $1 \mathrm{MHz}$ ) are higher than those of the epoxy (3.9 and 0.015 , as measured at $1 \mathrm{MHz}$ ). Furthermore, it is known that dielectric constant $\varepsilon$ of polymeric systems results from permanent dipole motion within the systems. Epoxy resin has a characteristically low $\varepsilon$ due to low polarity of the bisphenol-A unit. The addition of SiC particles, with its surface polar hydroxide groups, is thought to increase $\varepsilon$ of the composites. ${ }^{15}$

Besides dipolar polarization of polar groups, in the composites, there is another affecting term, viz., interfacial polarization. Interfacial polarization processes, known as Maxwell-Wagner-Sillar, produce an accumulation of charges on the interface, causing large-scale distortion. ${ }^{16}$ Since coupling agent efficiently improves the compatibility of heterophases in composites, weakening the interfacial electric field distortion, silane treatment of $\mathrm{SiC}$ particles decreases $\varepsilon$ of the composites, as shown in Figure 6.

Silane treatment of $\mathrm{SiC}$ particles weakens electric field distortion. The weakened electric field distortion promotes mobile dielectric dipoles easy to reorientate and rotate with the change of electric field, resulting in a decrease of relaxation polarization loss of the composites, thus silane treatment of $\mathrm{SiC}$ 


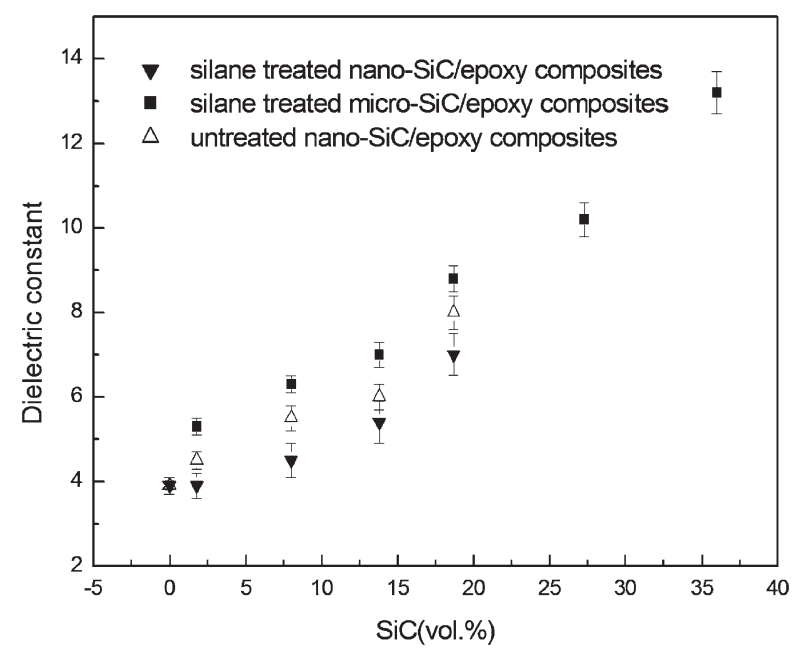

(a)

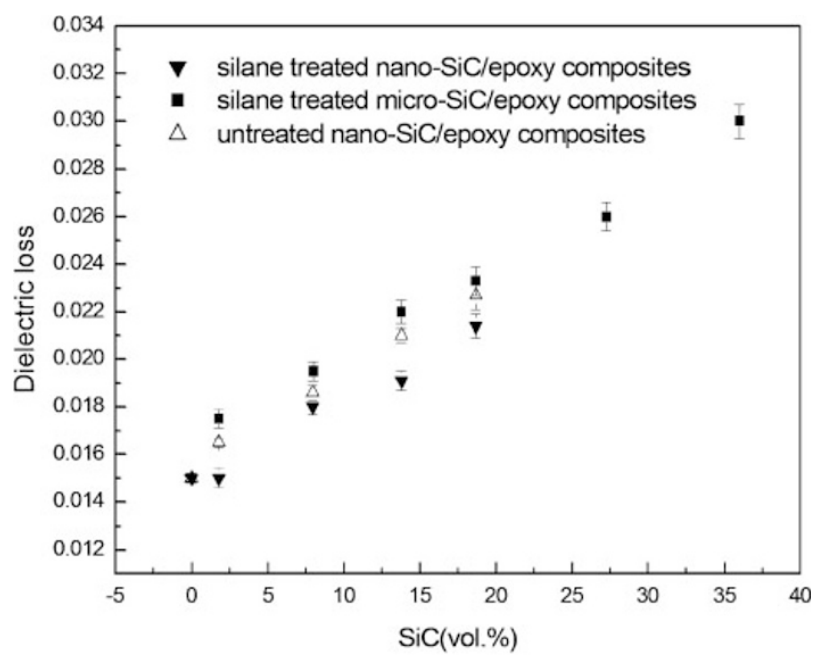

(b)

Figure 6. Plot of (a) dielectric constant and (b) dielectric loss of SiC/epoxy composites vs. volume fraction of $\mathrm{SiC}(1 \mathrm{MHz}$, room temperature).

particles decreases $\tan (\delta)$ of the composites, as shown in Figure 6. Furthermore, silane treatment of $\mathrm{SiC}$ particles strengthens interfacial interaction, reducing the amount of mobile dielectric dipoles, which also contributes to the $\tan (\delta)$ decrease of the composites.

Stronger interfacial reaction in nanocomposites leads to a more decrease in the amount of mobile dielectric dipoles, and thereby a more decrease in $\tan (\delta) .{ }^{16}$ As seen in Figure 6, with same filler content, measured $\tan (\delta)$ follows the sequence: treated nano-SiC/epoxy composites $<$ treated micro-SiC/epoxy composites.

Figure 7 shows the influence of temperature on $\varepsilon$ and $\tan (\delta)$ for 8 vol. $\%$ silane treated $\mathrm{SiC}$ filled epoxy composite in the temperature range $20-170^{\circ} \mathrm{C}$ and at $1 \mathrm{MHz}$ frequency. It was observed that there was not much characteristic variation of dielectric properties, indicating good temperature independence of dielectric properties which meets the demand of some microelectronics materials.

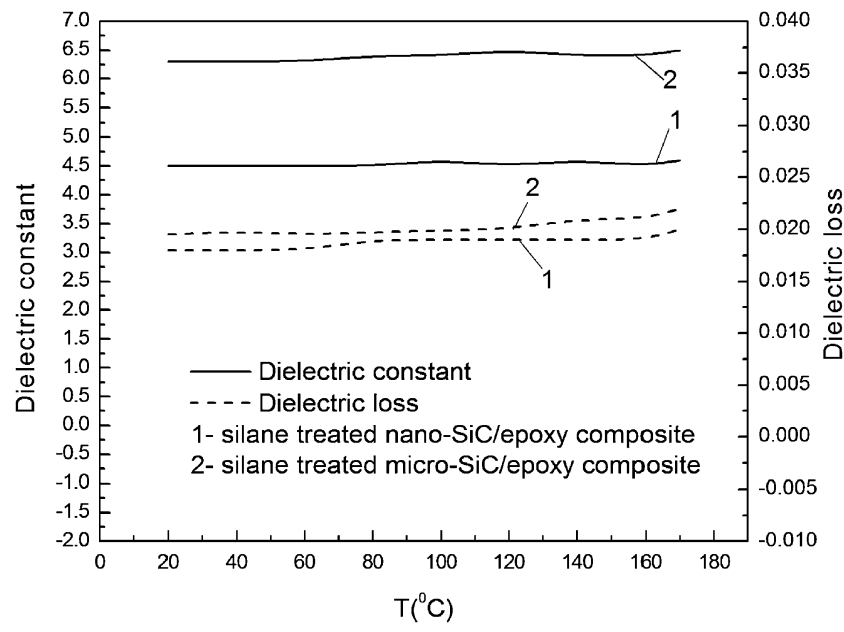

Figure 7. Variation of dielectric properties versus temperature for $8 \mathrm{vol}$. $\%$ silane treated $\mathrm{SiC}$ filled epoxy composite at $1 \mathrm{MHz}$ frequency.

Table II. Volume resistivity of the SiC/epoxy composites

\begin{tabular}{cc}
\hline Sample & $\begin{array}{c}\text { volume resistivity } \\
(\Omega \cdot \mathrm{cm} \text {, room temperature })\end{array}$ \\
\hline Pure system & $1.15 \times 10^{15}$ \\
1.79 vol. \% treated nano-SiC/epoxy composite & $7.38 \times 10^{14}$ \\
8 vol. \% treated nano-SiC/epoxy composite & $1.55 \times 10^{14}$ \\
13.8 vol. \% treated nano-SiC/epoxy composite & $9.04 \times 10^{13}$ \\
1.79 vol. \% untreated nano-SiC/epoxy composite & $1.35 \times 10^{14}$ \\
8 vol. \% untreated nano-SiC/epoxy composite & $7.14 \times 10^{13}$ \\
13.8 vol. \% untreated nano-SiC/epoxy composite & $6.64 \times 10^{13}$ \\
1.79 vol. \% treated micro-SiC/epoxy composite & $3.25 \times 10^{13}$ \\
8 vol. \% treated micro-SiC/epoxy composite & $8.08 \times 10^{12}$ \\
13.8 vol. \% treated micro-SiC/epoxy composite & $7.12 \times 10^{12}$ \\
\hline
\end{tabular}

From the application point of view, some electronic package materials must be electrical insulating. ${ }^{17}$ Since $\mathrm{SiC}$ is somewhat semiconductor, the volume resistivity of epoxy composites was a key concern. The studied SiC/epoxy composites, as shown in Table II, are confirmed to be insulators. Addition of $\mathrm{SiC}$ particles leads to decreased volume resistivity of the composites. Silane treatment of nano-SiC particles increases surface energy of the particles, promoting particles to adsorb charge carriers in the composites, thus the reduced concentration of free charge carriers leads to an increase in volume resistivity of the composites. Therefore, silane treatment of nano-SiC particles increases volume resistivity of the composites. It is also seen that volume resistivity of nanocomposites is higher than that of microcomposites.

\section{CONCLUSION}

This report covers the results of a study on evaluating the effect of nano-SiC particles on mechanical, thermal and electrical properties of epoxy by lap shear, TGA, DSC and electrical tests. Epoxy composites filled with micro-SiC particles were also studied for comparison. The results showed that with identical loading, silane treated nano-SiC filled 
nanocomposites have the best properties. The volume resistivity decrease, $\varepsilon$ increase and $\tan (\delta)$ increase by addition of silane treated nano-SiC particles are smaller than those by the other fillers. Silane treatment of nanoparticles improves each performance, including increases shear strength, thermal stability, volume resistivity and decreases $\varepsilon$ and $\tan (\delta)$.

Lap shear tests showed that shear strength has a sharp improvement with increasing silane treated nano-SiC content, reaches the maximum, and then decreases with the increasing filler content. 8 vol. \% silane treated nano-SiC/epoxy composite has the highest shear strength 10.6 MPa with the maximum enhancement, $80 \%$, over the neat resin. Shear fracture morphology showed that nanocomposites are more of a ductile nature as opposed to a brittle failure in case of microcomposites, which causes their higher shear strength.

TGA and DSC tests showed that the content and size of SiC don't affect the degradation pattern of the SiC/epoxy composites, and the addition of nano-SiC particles slightly enhances thermal stability of epoxy.

Electrical tests showed that the addition of silane treated nano-SiC filler gives smaller $\varepsilon$ and $\tan (\delta)$ than the other fillers. 8 vol. \% silane treated nano-SiC/epoxy composite has good temperature independence of dielectric properties and enough volume resistivity, which meet the demand of some microelectronics materials.

Acknowledgment. The authors are grateful for the financial support of National Natural Science Foundation of China (No. 10776014), China Postdoctoral Science Foundation funded project (No. 20080431103), High Technical Foundation of Jiangsu Province of China (No. BG2007047), Natural Science Foundation of Jiangsu Province of China (No. BK2008407), Jiangsu Planned Projects for Postdoctoral Research Funds (No. 0801023B), Special Foundation for Young Scholars of Nanjing University of Science \& Technology
(No. AB41339) and Starting Foundation for Scholars of Nanjing University of Science \& Technology (No. AB41980).

Received: August 5, 2008

Accepted: September 27, 2008

Published: November 12, 2008

\section{REFERENCES}

1. E. Reynaud, C. Gauthier, and J. Perez, Rev. Metall./Cah. Inf. Tech., 96, 169 (1999).

2. P. Liu, M. Zhao, and J. Guo, J. Macromol. Sci., Part B: Phys., 45 1135 (2006).

3. F. Bauer, U. Decker, H. Ernst, M. Findeisen, H. Langguth, R. Mehnert, V. Sauerland, and R. Hinterwaldner, Int. J. Adhes. Adhes., 26, 567 (2006).

4. N. Chisholm, H. Mahfuz, V. K. Rangari, A. Ashfaq, and S. Jeelani, Compos. Struct., 67, 115 (2005).

5. Q. L. Ji, M. Q. Zhang, M. Z. Rong, B. Wetzel, and K. Friedrich, Tribol. Lett., 20, 115 (2005).

6. R. M. Rodgers, H. Mahfuz, V. K. Rangari, N. Chisholm, and S. Jeelani, Macromol. Mater. Eng., 290, 423 (2005).

7. J. W. Gilman, Appl. Clay Sci., 15, 31 (1999).

8. C. S. Reddy and C. K. Das, J. Appl. Polym. Sci., 102, 2117 (2006).

9. A. Mahmood, S. Muhl, R. Machorro, A. Lousa, J. Esteve, and J. Heiras, Diamond Relat. Mater., 15, 71 (2006).

10. T. Zhou, M. Gu, Y. Jin, and J. Wang, Polymer, 46, 6216 (2005).

11. T. Zhou, X. Wang, M. Gu, and X. Liu, Polymer, 49, 4666 (2008).

12. I. L. Dubnikova, S. M. Berezina, and A. V. Antonov, J. Appl. Polym. Sci., 94, 1917 (2004).

13. Y. Sun, Z. Zhang, and C. P. Wong, presented at IEEE, 9th International Symposium and Exhibition on Advanced Packaging Materials. Processes Prop Interfaces, 2004.

14. Y. Sun, Z. Zhang, K.-S. Moon, and C. P. Wong, J. Polym. Sci., Part B: Polym. Phys., 42, 3849 (2004).

15. T. J. Wooster, S. Abrol, J. M. Hey, and D. R. MacFarlane, Composite Part A: Applied Science and Manufacturing, 35, 75 (2004).

16. L. Ramajo, M. Reboredo, and M. Castro, Composites Part A: Applied Science and Manufacturing, 36, 1267 (2005).

17. H. Li, K. I. Jacob, C. P. Wong, and I. Fellow, IEEE Trans. Adv. Packag., 26, 25 (2003). 